\title{
Application of the Theory of Planned Behaviour to weight control in an overweight cohort: results from a pan-European dietary intervention trial (DiOGenes)
}

Aine McConnon ${ }^{a}$, Monique Raats ${ }^{a}$, Arne Astrup ${ }^{b}$, Magda Bajzovác, Teodora Handjieva-Darlenska ${ }^{d}$, Anna Karin Lindroos ${ }^{\mathrm{e}}$, Alfredo Martinez ${ }^{\mathrm{f}}$, Thomas Meinert Larson ${ }^{\mathrm{b}}$, Angeliki Papadaki ${ }^{\mathrm{b}}$, Andreas Pfeiffer ${ }^{\text {h }}$, Marleen A. van Baak', Richard Shepherd ${ }^{\mathrm{a}}$

${ }^{a}$ Food, Consumer Behaviour and Health Research Centre, Department of Psychology, University of Surrey, Guildford, Surrey, GU2 7XH, UK.

${ }^{b}$ Department of Human Nutrition, Faculty of Life Sciences, University of Copenhagen, Denmark.

'Charles University in Prague, Third Faculty of Medicine, Department of Sport Medicine, Ruská 87, 10000 Prague 10, Czech Republic.

${ }^{d}$ National Multiprofile Transport Hospital, Sofia, Bulgaria.

e MRC Human Nutrition Research, Elsie Widdowson Laboratory, Cambridge, CB1 9NL, UK.

fUniversity of Navarra, Department of Physiology and Nutrition, Navarra, Spain.

${ }^{\mathrm{g}}$ Department of Social Medicine, Preventive Medicine \& Nutrition Clinic, PO Box 2208, Heraklion, 710 03, Crete, Greece.

heptartment of Clinical Nutrition, German Institute of Human Nutrition, Potsdam, Arthur-Scheunert Allee 114-116, 14558 Nuthetal, Germany.

'NUTRIM, School for Nutrition, Toxicology and Metabolism, Department of Human Biology, Maastricht University Medical Center, P.O. Box 616, 6200MD Maastricht, The Netherlands.

\begin{abstract}
:
Using the Theory of Planned Behaviour (TPB), this study investigates weight control in overweight and obese participants $\left(27 \mathrm{~kg} / \mathrm{m}^{2} \leq \mathrm{BMI}<45 \mathrm{~kg} / \mathrm{m}^{2}\right)$ taking part in a dietary intervention trial targeted at weight loss maintenance ( $n=932$ ). Respondents completed TPB measures investigating "weight gain prevention" at three time points. Correlation and regression analyses were used to investigate the relationship between TPB variables and weight regain. The TPB explained up to $27 \%$ variance in expectation, $14 \%$ in intention and $20 \%$ in desire scores. No relationship was established between intention, expectation or desire and behaviour at Time 1 or Time 2. Perceived need and subjective norm were found to be significantly related to weight regain, however, the model explained a maximum of $11 \%$ of the variation in weight regain. Better understanding of overweight individuals' trajectories of weight control is needed to help inform studies investigating people's weight regain behaviours. Future research using the TPB model to explain weight control should consider the likely behaviours being sought by individuals.
\end{abstract}

Keywords: Obesity, weight maintenance, Theory of Planned Behaviour, dietary intervention 


\section{Introduction:}

Overweight is believed to affect $30-80 \%$ of adults in Europe with the prevalence of obesity rising rapidly (Branca, Nikogosian, \& Lobstein, 2007). Obesity is understood to be the result of long-term energy intake greater than energy expenditure, resulting in positive energy imbalance. This disequilibrium can arise from an excess in calorie intake and/or a deficit in calorie expenditure (lack of physical activity). However, obesity is recognised as a heterogeneous condition and it is accepted that large individual differences in people's ability to control their body weight exist (Schifter \& Ajzen, 1985; Teixeira, Going, Sardinha, \& Lohman, 2005). Individual differences in behaviours closely related to energy balance or weight control, determine the development of overweight and obesity. The benefits of weight loss and weight loss maintenance have been well documented (Vidal, 2002). However, current approaches to overweight and obesity management have shown limited effectiveness, especially over the long term, with weight loss maintenance presenting a particularly difficult challenge (Elfhag \& Rössner, 2005; Garcia Ulen, Huizinga, Beech, \& Elasy, 2008; Wadden, Brownell, \& Foster, 2002; Wing \& Hill, 2001). Better understanding of individuals' behaviours and the differences in behaviours of those who are successful and unsuccessful at weight control will enable development of more targeted treatment options.

A number of behavioural models for understanding health behaviours, such as weight control exist, one of which is the Theory of Planned Behaviour (TPB). The TPB was first developed by Ajzen in the 1980s (Schifter \& Ajzen 1985, Ajzen, 1991) and is one of the most widely used theoretical frameworks for explaining health behaviours (Godin \& Kok, 1996). The TPB has been applied to a range of diet and weight related behaviours including fat intake (de Bruijn, Kroeze, Oenema, \& Brug, 2008; Paisley \& Sparks, 1998) and fruit and vegetable consumption (Bogers, Brug, Van Assema, \& Dagnelie, 2004; Kellar \& Abraham, 2005; Lien, Lytle, \& Komro, 2002; Perugini \& Bagozzi, 2004); healthy eating behaviour (Conner, Norman, \& Bell, 2002; Povey, Conner, Sparks, James, \& Shepherd, 2000c) and weight control (Netemeyer, Burton, \& Johnston, 1991; Palmeira et al., 2007; Schifter \& Ajzen, 1985). The TPB suggests that the best predictor of actual behaviour is a person's intention to perform the behaviour. Intention is in turn determined by three independent constructs: attitude, subjective norms, and perceived behavioural control (PBC). Attitudes relate to the individual's evaluation of the behaviour, subjective norms reflect an individual's perception that important others expect them to perform the behaviour, and PBC is an individual's perception of how much control they have over performing the behaviour. $\mathrm{PBC}$ is said to refer to the perceived ease or difficulty of performing a certain behaviour (Ajzen, 1998) and is believed to determine both intention and actual behaviour. The TPB proposes that a more positive attitude towards a behaviour, together with a supportive subjective norm and higher perceived behavioural control, will result in a stronger intention to perform the behaviour and subsequently more likelihood of the behaviour being performed.

Although traditionally the TPB focused simply on prediction of intention and thus behaviour, this focus expanded quite early on with desire and expectation both believed to play a role in predicting behaviour (Bagozzi, 1992; Warshaw \& Davis, 1985). Previous studies have demonstrated close relationships between intention, desire, and expectation in predicting behaviour using the TPB model (Armitage \& Conner, 2001; Fishbein \& Stasson, 1990; Warshaw \& Davis, 1985). Expectations and desires have both been shown to be better than intentions at predicting behaviour (Fishbein \& Stasson, 1990; Warshaw \& Davis, 1985). One meta-analytical review concluded that perceived behavioural control, subjective norm, and attitude were better at predicting desire than they were at predicting intention, whereas intentions and expectations were better than desires at predicting actual behaviour (Armitage \& Conner, 2001). In relation to behaviours which an individual may not have complete volitional control over, expectation is of particular importance as it is said to consider those unintentional determinants of behaviour (Warshaw \& Davies, 1985) which is likely to apply to a behaviour such as weight control. Therefore, it is important to investigate the relationship 
between expectation, desire, and intention, and the role of the other predictors in explaining these three variables.

A review by Armitage and Conner (2001) meta-analysed 185 studies which applied the TPB, and reported that the TPB accounted for $27 \%$ and $39 \%$ of the variance in behaviour and intention, respectively (Armitage \& Conner, 2001). More recently, efforts to increase predictive capacity of the traditional model have led to the addition of other constructs which have included anticipated affect (Raats, Sparks, Geekie, \& Shepherd, 1999; Richard, van der Pligt, \& de Vries, 1996) and perceived need (Paisley \& Sparks, 1998; Payne, Jones, \& Harris, 2004; Povey, Conner, Sparks, James, \& Shepherd, 2000a; Raats, et al., 1999). Anticipated affect measures expected reaction from a particular outcome or behaviour which could be expected to be of importance when the behaviour relates to weight control (i.e. expected good feeling about "preventing weight gain"). Perceived need is a measure of the extent to which it is felt necessary to perform the behaviour in question (Raats, et al., 1999). Both constructs have been shown to have an additive effect when included in the TPB model (Paisley \& Sparks, 1998, Richard, van der Pligt, \& de Vries, 1996; Parker, Stradling, \& Manstead, 1996).

This study attempts to further our understanding of weight control by examining the relationship between the cognitions underlying weight regain of individuals enrolled in a dietary intervention study for weight loss maintenance. This paper investigates the relationship between the various components of the TPB model and intention, expectation and desire to prevent weight gain, as well as actual weight regain behaviour. It is hypothesised that a positive association between the TPB model and intention, expectation and desire, and a negative association with weight regain will be revealed. In addition, given the nature of the behaviour in question, it is hypothesised that the TPB items will be more successful in predicting expectation, over intention and desire and thus in turn that expectation will relate more closely to the behaviour, than either intention or desire.

\section{Methods}

\section{Study sample:}

Reported data were collected as part of the Diogenes study, a Pan-European, randomised, controlled dietary intervention study investigating the effects of dietary protein and glycemic index on weight (re)gain, metabolic and cardiovascular risk factors in obese and overweight families in eight European centres (www.diogenes-eu.org). A detailed description of the Diogenes intervention trial can be found elsewhere (Larsen et al., 2010a; Moore et al., 2010; Saris \& Harper, 2005).

The aim of this intervention trial was to investigate factors influencing weight maintenance following a period of rapid weight loss. In brief, this randomised trial consisted of 2 phases. The first was an 8week weight-loss phase during which participants followed a fixed low calorie diet (LCD) and expected to lose at least $8 \%$ of their body weight. Following successful completion of this weight loss phase participants were randomised to one of five ad libitum (no restriction on total energy intake) low fat diets for 6 months. The second phase of the study (the randomised phase) was designed to promote weight loss maintenance (or prevent weight regain).

Families eligible for inclusion consisted of at least one overweight $\left(\mathrm{BMI}>27 \mathrm{~kg} / \mathrm{m}^{2}\right)$, but otherwise healthy parent aged less than 65 years with at least one healthy child between 5 and 18 years of age. The complete list of inclusion and exclusion criteria has been published previously (Larsen et al., 2010a). 932 adults from eight European countries participated in the trial.

The families were provided with recipes, together with cooking and behavioural advice, during the study. Specific details on the diets and the dietary counselling are given in a separate publication (Moore et al., 2010). 
Participants were asked to complete a battery of psychological, social, and demographic questionnaires at three time points during the study. These time points are shown in Figure 1. Participants first completed the questionnaires prior to commencement of the 8-week weight loss phase (Time 1, "pre-weight loss"). The questionnaires were completed again at the end of the 8week weight loss phase (which was also the start of the randomised phase of the study) (Time 2, "post-weight loss") and at the end of the six month randomised phase of the study (Time 3, "postweight maintenance"). Questionnaire data were collected for adult participants only, via a webbased platform, and participants completed questionnaires in the clinical investigation centres. The sample were ( $N=932$ adults) aged between 36 and 54 years ( $m=41$ years) of which $66 \%$ were female and $34 \%$ male.

\section{Questionnaire data:}

Participants completed the theory of planned behaviour measures at three time points. The questionnaire items were based on those used in previous studies (Povey et al., 2000c; Raats et al., 1999) and questions related to "prevention of weight gain in the next six months" as follows:

Intention to prevent weight gain was assessed with two items ("I intend to prevent weight gain in the next 6 months" and "I plan to prevent weight gain in the next 6 months") on a five point Likert scale ( $1=$ definitely do not agree; $5=$ definitely do agree). Correlation coefficients were $0.66,0.77$, $0.66(p<0.001)$ at Time 1,2 and 3, respectively.

Attitude toward preventing weight gain was assessed with 5 items. The cognitive aspect of attitude was assessed on the scales harmful or beneficial; foolish or wise and bad or good on a five point Likert scale ( $1=$ extremely harmful, extremely foolish, extremely bad; $5=$ extremely beneficial, extremely wise, extremely good). Cronbach's alphas were $0.72,0.72,0.78$ at Time 1,2 and 3 , respectively. Affective attitude was assessed with two items asking how unenjoyable or enjoyable and unpleasant or pleasant prevention of weight gain would be (1= extremely unenjoyable, extremely unpleasant; 5 = extremely enjoyable, extremely pleasant). Respective Cronbach's alphas were $0.48,0.52,0.41$ at Time 1,2 and 3. Reliability of these constructs is low and therefore they need to be treated with caution.

Subjective norm was assessed with 4 items by asking participants if "people who are important to me" think I should prevent weight gain; would approve/disapprove; want me to and "I feel under social pressure to..." ( $1=$ totally disagree; $5=$ totally agree). Cronbach's alpha values were $0.71,0.68$, 0.76 at Time 1, 2 and 3, respectively.

Perceived behavioural control was assessed with 3 items ("How easy or difficult would it be for you to prevent weight gain in the next 6 months?", "Whether I do or do not prevent any weight gain in the next 6 months is entirely up to me.", "How much control do you feel you have over preventing weight gain over the next 6 months?") on a five point Likert scale (1= extremely difficult, strongly disagree, no control; 5 = extremely easy, strongly agree, complete control). Cronbach's alpha values were $0.44,0.46,0.53$ at Time 1,2 and 3 , respectively. Reliability of these constructs is low and therefore they need to be treated with caution.

Desire was assessed using 2 items asking the participant if they "would like to" and if they "want to" prevent weight gain in the next six months, on a five point Likert scle (1= definitely no, strongly disagree; 5 = definitely yes, strongly agree. Correlation coefficients were $0.45,0.51,0.58(p<0.001)$ at Time 1,2 and 3 , respectively.

Expectation was assessed using 2 items ("I expect to prevent weight gain in the next 6 months" and "How unlikely or likely is it that you will prevent weight gain in the next 6 months?") on a five point Likert scale ( $1=$ extremely unlikely; $5=$ extremely likely). Correlation coefficients were $0.56,0.64,0.70$ $(p<0.001)$ at Time 1,2 and 3 , respectively. 
Anticipated affect was measured using a single item (How displeased or pleased would you be if you managed to prevent weight gain in the next 6 months? $1=$ extremely displeased; $5=$ extremely pleased).

Perceived need was also measured using a single item (To what extent do you feel that you need to prevent weight gain in the next 6 months? $1=$ definitely do not need to; $5=$ definitely need to).

\section{Weight data:}

In addition to the questionnaire data, body weight was measured at each visit to the clinical investigation centre. For the purpose of this paper, weights at the three time points where the questionnaire data were completed are used (see figure 1). Using the weight data at these time points, an overall weight regain score was computed, which was calculated as weight change during the randomised phase of the study (Time 3 minus Time 2), divided by weight loss during the 8-week weight loss phase (Time 2 minus Time 1). This variable is used in order to account for the influence of initial weight loss during the initial 8 week rapid weight loss phase on weight change during the randomised phase of the study. Weight loss and regain results from the trial have been published elsewhere (Larsen, et al., 2010b).

\section{Data analysis:}

SPSS v15 was used (SPSS, Chicago, IL). Correlation analysis was used to investigate the relationship between the variables of the TPB model. Multiple regression analysis was conducted to assess the association with TPB measures at the three time points, with intention, expectation and desire. Associations between weight at Time 1 as well as weight regain during the study and the TPB measures (at Time 1 and Time 2 ) were examined using multiple regressions. The analysis presented is based on completers only (those for whom data were available at all three time points) $(n=515)$. Analysis was also conducted using all participants ( $n=920$ at Time $1, n=767$ at Time $2, n=550$ at Time $3)$, but no major differences in results were seen between the two sets of analyses. Initial ANOVA analysis was conducted to investigate if any differences existed between the five different diets. However, no differences between the five diets were revealed, therefore dietary group is not accounted for in the analysis presented in this paper.

\section{Results:}

\section{Relationship between TPB variables:}

As expected, intention, expectation, and desire scores were found to be positively related to each other with moderate, significant, correlations of between 0.18 and 0.50 revealed $(p<0.001)$. To investigate the relationship between the TPB variables and intention, expectation, and desire, the TPB variables were entered into separate regression models (Table 1).

Predicting Intention: The results in Table 1 show that only perceived need significantly predicted intention at Time 1. At Time 2, affective attitude along with anticipated affect and perceived need significantly predicted intention. By Time 3 , all predictors remained significant, except for anticipated affect; with perceived control becoming a significant predictor of intention to prevent weight gain. Over time, perceived need was the only consistent predictor of intention, with higher perceived need correlated with higher intention scores. These analyses explained a maximum of $14 \%$ of the variance in intentions to prevent weight gain in the next 6 months.

Predicting Expectation and Desire: Table 1 also shows the relationships between the TPB variables and expectation and desire scores. Perceived need also significantly predicted desire scores at each time point as well as expectation scores at Time 1 and Time 2. Perceived behavioural control was 
shown to significantly predict expectation scores at all time points. Anticipated affect (Time 3 ) and subjective norm (Time 2) were significant predictors of expectation. Cognitive attitude, subjective norm and anticipated affect significantly predicted desire scores at Time 2 and Time 3, while perceived behavioural control was significant in predicting desire at Time 3 . These models were shown to explain $21 \%$ and $18 \%$, respectively, of the variance in expectation and desire scores at Time 2 and $27 \%$ and $20 \%$, respectively, at Time 3 . As expected, the analysis revealed the TPB to be most predictive of expectation, rather than either intention or desire.

Preventing weight regain: The relationship between the TPB variables at Time 1 (pre-weight loss) and Time 2 (post-weight loss) and weight regain was explored. A negative correlation indicates more weight regain is associated with lower TPB variable scores. No significant relationships between intention, expectation or desire and weight regain at Time 1 or Time 2 were revealed. Time 1 scores for affective attitude $(0.13, p=0.001)$, subjective norms $(-0.16, p<0.001)$, perceived behavioural control $(0.10, p=0.02)$ and perceived need $(0.29, p<0.001)$ were all found to be correlated with weight regain. Similarly Time 2 scores for affective attitude $(0.16, p<0.001)$, subjective norm $(-0.10$, $p=0.03)$ and perceived need $(0.25, p<0.001)$ were also found to be significantly correlated with weight regain.

Those variables found to be significantly correlated with weight regain were entered into a regression model (controlling for start weight) (Table 2). Subjective norm scores at Time 1 and Time 2 were shown to be negatively related to weight regain, suggesting that as subjective norm scores increase, weight regain decreases. In addition, a significant, positive, relationship was detected between perceived need and weight regain scores at Time 1 and Time 2, suggesting that as perceived need scores increased, weight regain also increased.

\section{Discussion:}

This research used the TPB to predict weight gain intentions (expectations and desires) and behaviour of overweight individuals participating in an intervention programme targeted at weight loss followed by weight maintenance or weight regain prevention.

The TPB model was found to be more effective in predicting expectation than intention or desire, as was hypothesised. The model explained $14 \%$ of the variance in expectation at Time 1 and $21 \%$ and $27 \%$ of expectation at Time 2 and Time 3, respectively, compared to 7\%, 9\% and 14\% of the variance in intention and $5 \%, 18 \%$ and $20 \%$ of the variance in desire at the three time points. Similar analysis by Armitage and Conner (2001) showed that the TPB variables were least closely associated with intention compared with desire and expectation (Armitage \& Conner, 2001). Behavioural expectation is said to incorporate unintentional determinants of behaviour, which is of particular importance for behaviours over which individuals do not have complete volitional control, such as weight control. It has been suggested that individuals consider their degree of volitional control, as well as other possible impediments to performing the behaviour, in their judgement of expectation (Warshaw \& Davis, 1985). Therefore, it is unsurprising that expectation is best explained by the TPB for controlling weight.

Although perceived need was the strongest predictor of intention, by Time 3 cognitive attitude was shown to be a significant predictor of intention. Cognitive attitude is a measure of cognitive or nonemotional belief. The increase in the role of cognitive attitude in predicting intention to control weight may mean that by the end of the study, participants' cognitive response became more important in predicting their intention to control weight in the future. A similar trend is also seen for desire, but not for expectation. 
Perceived behavioural control was the most consistent predictor of expectation, with the strength of association increasing over time. Higher PBC predicted higher expectation to perform the behaviour, suggesting that those who felt they had control over their weight, expected to be more successful in controlling their weight. A similar relationship between intention or desire and PBC was not found.

Thus, although PBC does not appear to have the same influence on one's intention or desire to carry out the behaviour, it does increase one's expectation that they will control their weight. This intention - PBC - expectation relationship has been noted elsewhere (Warshaw \& Davis, 1985). Armitage and Conner (2001) suggest that as desires do not take account of influences which may inhibit behaviour, PBC could be more closely related to expectations than with desires and the same could be true for intentions (Armitage \& Conner, 2001). Expectation incorporates an element of control that is not the case with intentions. It may be that a person has strong intentions of performing a behaviour, but because of low perceptions of control over the behaviour they may not have positive expectations of performing the behaviour (Paisley \& Sparks, 1998). According to the TPB model, PBC is also believed to have an independent effect on behaviour, however this was not found to be the case in this study.

Anticipated affect and perceived need were both shown to play a significant role in the prediction of intention, desire and expectation suggesting that the extended TPB model offers better explanation of the behaviour than the original TPB model.

Previous studies have demonstrated close relationships between intention, desire, and expectation in predicting behaviour using the TPB model (Armitage \& Conner, 2001; Fishbein \& Stasson, 1990; Warshaw \& Davis, 1985). Initial correlation analyses failed to show a significant relationship between intention and behaviour at any of the time points. This finding is supported by previous research in this area, where intentions failed to predict weight loss (Netemeyer et al., 1991; Schifter \& Ajzen, 1985). This outcome again may suggest that weight control is a non-volitional behaviour, making it difficult to detect a direct relationship between intention and behaviour (Bagozzi \& Edwards, 1998). The current analysis explained a maximum of $11 \%$ of the variance in weight regain behaviour. Only a few studies have used the TPB to examine weight control specifically, as opposed to applying the theory to behaviours leading to weight control (e.g. healthy eating, low fat diet, exercise)

(Netemeyer et al., 1991; Schifter \& Ajzen, 1985). These two studies explained $7.9 \%$ and $19.4 \%$ of the variance in weight loss using the TPB. A study by Palmeira et al. (2007) explained $14.8 \%$ of the variance in weight management behaviours using intentions, attitude, subjective norm and $\mathrm{PBC}$ (attitude and PBC were significant in the model) (Palmeira et al., 2007). However, it is important to note that the current study investigated weight gain prevention, rather than weight loss. The TPB is based on measuring factors likely to influence people's intention of performing a behaviour that a person has thoughts of achieving, therefore it is important that the behaviour being explained is one recognised as something participants want to achieve. Work by Bagozzi and Edwards $(1998,2000)$ investigating the role of goal setting and attainment in relation to body weight regulation has compared different weight control strategies and concluded that the level of difficulty in implementing the behaviour influences the initiation of the behaviour (Bagozzi \& Edwards, 1998, 2000). Prevention of weight gain is likely to be viewed by individuals as a different behaviour to weight loss, and one that is not necessarily one people want to achieve, particularly in overweight and obese individuals. Policy recommendations setting out a weight loss of $5-10 \%$ followed by weight maintenance as "successful", are known to be at odds with the goals or expectations of those trying to achieve "successful" body weight (Foster, Wadden, Vogt, \& Brewer, 1997; Wadden et al., 2003). Individuals trying to lose weight are more likely to set a target two to three times higher than those offered by the best available treatments (Foster et al., 1997; Linde, Jeffery, Finch, Ng, \& Rothman, 2004). Overall, low predictive power of the models may be explained by the suggestion that the behaviour investigated (prevention of weight gain) was not the behaviour that participants were aiming to achieve (continued weight loss). 
Perceived need and subjective norm were shown to be the most significant predictors of behaviour (actual weight control). The most important predictor of behaviour was perceived need, at both time points, adding $7 \%$ to the explanation of the variance in weight regain behaviour. This figure is in the range of that found in previous studies which looked at healthy eating behaviours (3-11\%) (Paisley \& Sparks, 1998; Payne et al., 2004; Povey, Conner, Sparks, James, \& Shepherd, 2000b). Although small, the contribution made by perceived need to the model was greater than the combined contribution of subjective norm, PBC and attitude. Perceived need to control weight was the most consistent significant positive predictor of expectation, intention and desire at all three time points, such that as perceived need increased, expectation, desire, and intention to control weight also increased. Paisley and Sparks (1998) refer to Prochaska and DiClemente's transtheoretical or stages of change model (Prochaska \& DiClemente, 1982) in relation to this positive association between need and expectation, suggesting that a low need score suggests lack of contemplation for making behaviour change (Paisley \& Sparks, 1998).

Similar to other studies, perceived need was found to be a significant predictor of intention (Payne et al., 2004; Raats et al., 1999) as well as the most significant predictor of behaviour. However, the direction of this relationship was the opposite of that found in previous research (Payne et al., 2004; Raats et al., 1999). This finding suggests that those with a higher perceived need to prevent weight gain regained more weight. This finding may suggest that heavier participants were more likely to recognise the need to prevent weight gain and may show greater weight regain merely as a result of being more overweight. However, the weight gain formula should have accounted for this possibility, as well as inclusion of starting weight as a variable in the regression analysis. As discussed previously this research examined weight gain prevention, rather than weight loss. It may be that this inverse relationship is explained by participants' interpretation of the behaviour in question and that weight gain prevention was not in fact a behaviour that participants sought but that they were hoping to continue losing weight. As suggested previously, preventing weight gain may have been a difficult concept for participants to relate to, and not something they were seeking, but rather that they may have been seeking continued weight loss throughout the study. This does suggest a possible measurement issue in this study, that participants weren't answering the questions based on the behaviour of interest (weight gain prevention), but rather, based on a different behaviour (weight loss). In order to disentangle this issue, it may have been optimal to ask participants about both weight loss and weight gain prevention.

This study had a number of important strengths worth noting. A major strength of this study is the use of a well validated model of behaviour change to examine an increasingly important healthrelated behaviour. The large sample size and an objective outcome or behavioural measure are also two major strengths of this study. Many studies to date have tended to focus on weight loss rather than weight maintenance. A recent paper concluded that successful weight loss is not the barrier to successful weight control, but rather the successful prevention of weight regain (Garcia et al., 2008). More emphasis on weight maintenance, following weight loss, is likely to produce better long-term weight outcomes.

It is also important that some limitations of this study are considered when interpreting the results of this analysis. Perceived need and anticipated affect were both measured using single items which may undermine their reliability. However single item construct measurement is common practice in the literature (Paisley \& Sparks, 1998; Payne et al., 2004; Raats et al., 1999) and allows comparability of results. Also the reliability scores for a number of the constructs were quite low, namely affective attitude and PBC. Low inter-item reliability for the three items used to assess PBC has been reported in a number of other studies (Sparks, Guthrie, \& Shepherd, 1997). In the current study, dropping an item from this measure made little difference to the internal reliability of this variable. It has been suggested in the literature that PBC can be divided into control and difficulty, and that these two aspects play separate roles in explaining intention or behaviour (Sparks et al., 1997). In relation to 
affective attitude, these items related to enjoyment and pleasure in relation to the behaviour of preventing weight gain. It may be that these concepts do not relate well to this behaviour.

Despite these limitations, the current analysis provides the first attempt to investigate weight gain prevention in an overweight cohort using the TPB. Better understanding of overweight individuals' trajectories of weight control is needed to help inform more successful interventions for weight control.

\section{Acknowledgements}

We thank the staff of the dietary intervention centres where the data were collected. The DiOGenes project is funded by a grant from the EU Food Quality and Safety Priority of the Sixth Framework Programme, contract no. FP6-2005-513946.

\section{Conflict of interest}

The authors declare no conflict of interest.

Ajzen, I. (1998). Models of human social behavior and their application to health psychology. Psychology \& Health, 13, 735 - 739.

Armitage, C., \& Conner, M. (2001). Efficacy of the theory of planned behaviour: A meta-analytic review. British Journal of Social Psychology, 40, 471-499.

Bagozzi, R. P. (1992). The self-regulation of attitudes, intentions, and behavior. Social Psychology Quarterly, 55, 178-204.

Bagozzi, R. P., \& Edwards, E. A. (1998). Goal setting and goal pursuit in the regulation of body weight. Psychology \& Health, 13, 593-621.

Bagozzi, R. P., \& Edwards, E. A. (2000). Goal-striving and the implementation of goal intentions in the regulation of body weight. Psychology \& Health, 15, 255-270.

Bogers, R. P., Brug, J., Van Assema, P., \& Dagnelie, P. C. (2004). Explaining fruit and vegetable consumption: the theory of planned behaviour and misconception of personal intake levels. Appetite, 42, 157-166.

Branca, F., Nikogosian, H., \& Lobstein, T. (2007). The challenge of Obesity in the WHO European Region and the Strategies for Response: Summary: World Health Organization.

Conner, M., Norman, P., \& Bell, R. (2002). The theory of planned behavior and healthy eating. Health Psychology, 21, 194-201.

de Bruijn, G., Kroeze, W., Oenema, A., \& Brug, J. (2008). Saturated fat consumption and the Theory of Planned Behaviour: Exploring additive and interactive effects of habit strength. Appetite, 51, 318-323.

Elfhag, K., \& Rössner, S. (2005). Who succeeds in maintaining weight loss? A conceptual review of factors associated with weight loss maintenance and weight regain. Obesity Reviews, 6, 6785.

Fishbein, M., \& Stasson, M. (1990). The Role of Desires, Self-Predictions, and Perceived Control in the Prediction of Training Session Attendance. Journal of Applied Social Psychology, 20, 173198. 
Foster, G., Wadden, T., Vogt, R., \& Brewer, G. (1997). What Is a Reasonable Weight Loss? Patients' Expectations and Evaluations of Obesity Treatment Outcomes* 1. Journal of Consulting and Clinical Psychology, 65, 79-85.

Garcia Ulen, C., Huizinga, M. M., Beech, B., \& Elasy, T. A. (2008). Weight Regain Prevention. Clinical Diabetes, 26, 100-113.

Godin, G., \& Kok, G. (1996). The theory of planned behavior: A review of its applications to healthrelated behaviors. American journal of health promotion, 11, 87-98.

Kellar, I., \& Abraham, C. (2005). Randomized controlled trial of a brief research-based intervention promoting fruit and vegetable consumption. In (Vol. 10, pp. 543-558): British Psychological Society.

Larsen, T., Dalskov, S.-M., van Baak, M., Jebb, S. A., Papadaki, A., Pfeiffer, A. F. H., Martinez, J. A., Handjieva-Darlenska, T., Kunešová, M., Pihlsgard, M., Stender, S., Holst, C., Saris, W. H. M., \& Astrup, A. (2010b). Diets with High or Low Protein Content and Glycemic Index for WeightLoss Maintenance. New England Journal of Medicine, 363, 2102-2113.

Larsen, T. M., Dalskov, S., van Baak, M., Jebb, S., Kafatos, A., Pfeiffer, A., Martinez, J., HandjievaDarlenska, T., Kunešová, M., \& Holst, C. (2010a). The Diet, Obesity and Genes (Diogenes) Dietary Study in eight European countries-a comprehensive design for long-term intervention. Obesity Reviews, 11, 76-91.

Lien, N., Lytle, L. A., \& Komro, K. A. (2002). Applying theory of planned behavior to fruit and vegetable consumption of young adolescents. 16, 189-197.

Linde, J., Jeffery, R., Finch, E., Ng, D., \& Rothman, A. (2004). Are Unrealistic Weight Loss Goals Associated with Outcomes for Overweight Women? . Obesity, 12, 569-576.

Moore, C., Lindroos, A., Kreutzer, M., Larsen, T., Astrup, A., van Baak, M., Handjieva-Darlenska, T., Hlavaty, P., Kafatos, A., \& Kohl, A. (2010). Dietary strategy to manipulate ad libitum macronutrient intake, and glycaemic index, across eight European countries in the Diogenes Study. Obesity Reviews, 11, 67-75.

Netemeyer, R., Burton, S., \& Johnston, M. (1991). A comparison of two models for the prediction of volitional and goal-directed behaviors: A confirmatory analysis approach. Social Psychology Quarterly, 54, 87-100.

Paisley, C., \& Sparks, P. (1998). Expectations of reducing fat intake: The role of perceived need within the theory of planned behaviour. Psychology \& Health, 13, 341-353.

Palmeira, A., Teixeira, P., Branco, T., Martins, S., Minderico, C., Barata, J., Serpa, S., \& Sardinha, L. (2007). Predicting short-term weight loss using four leading health behavior change theories. International Journal of Behavioral Nutrition and Physical Activity, 4, 14.

Parker, D., Stradling, S. G., Manstead, A. S. R. (1996) Modifying beliefs and attitudes to exceeding the speed limit: An intervention study based on the theory of planned behavior. Journal of Applied Social Psychology, 26, 1-19.

Payne, N., Jones, F., \& Harris, P. (2004). The role of perceived need within the theory of planned behaviour: a comparison of exercise and healthy eating. British Journal of Health Psychology, 9, 489-504.

Perugini, M., \& Bagozzi, R. (2004). The distinction between desires and intentions. European Journal of Social Psychology, 34, 69-84.

Povey, R., Conner, M., Sparks, P., James, R., \& Shepherd, R. (2000a). Application of the Theory of Planned Behaviour to two dietary behaviours: Roles of perceived control and self-efficacy. In (Vol. 5, pp. 121-139): British Psychological Society. 
Povey, R., Conner, M., Sparks, P., James, R., \& Shepherd, R. (2000b). Application of the Theory of Planned Behaviour to two dietary behaviours: Roles of perceived control and self-efficacy. British Journal of Health Psychology, 5, 121-139.

Povey, R., Conner, M., Sparks, P., James, R., \& Shepherd, R. (2000c). The theory of planned behaviour and healthy eating: Examining additive and moderating effects of social influence variables. Psychology \& Health, 14, 991-1006.

Prochaska, J., \& DiClemente, C. (1982). Transtheoretical therapy: Toward a more integrative model of change. Psychotherapy: Theory, Research and Practice, 19, 276-288.

Raats, M., Sparks, P., Geekie, M., \& Shepherd, R. (1999). The effects of providing personalized dietary feedback: A semi-computerized approach. Patient Education and Counseling, 37, 177-189.

Richard, R., van der Pligt, J., \& de Vries, N. (1996). Anticipated affect and behavioral choice. Basic and Applied Social Psychology, 18, 111-129.

Saris, W., \& Harper, A. (2005). DiOGenes: a multidisciplinary offensive focused on the obesity epidemic. Obesity Reviews, 6, 175-176.

Schifter, D., \& Ajzen, I. (1985). Intention, perceived control, and weight loss: An application of the theory of planned behavior. Journal of Personality and Social Psychology, 49, 843-851.

Sparks, P., Guthrie, C. A., \& Shepherd, R. (1997). The Dimensional Structure of the Perceived Behavioral Control Construct. Journal of Applied Social Psychology, 27, 418-438.

Teixeira, P., Going, S., Sardinha, L., \& Lohman, T. (2005). A review of psychosocial pre-treatment predictors of weight control. Obesity Reviews, 6, 43-65.

Vidal, J. (2002). Updated review on the benefits of weight loss. International Journal of Obesity, 26, 25-28.

Wadden, T., Brownell, K., \& Foster, G. (2002). Obesity: Responding to the global epidemic. Journal of Consulting and Clinical Psychology, 70, 510-525.

Wadden, T., Womble, L., Sarwer, D., Berkowitz, R., Clark, V., \& Foster, G. (2003). Great Expectations:" I'm Losing 25\% of My Weight No Matter What You Say". Journal of Consulting and Clinical Psychology, 71, 1084-1089.

Warshaw, P., \& Davis, F. (1985). Disentangling behavioral intention and behavioral expectation. Journal of Experimental Social Psychology, 21, 213-228.

Wing, R. R., \& Hill, J. O. (2001). Successful Weight Loss Maintenance. Annual Review of Nutrition, 21, 323-341. 


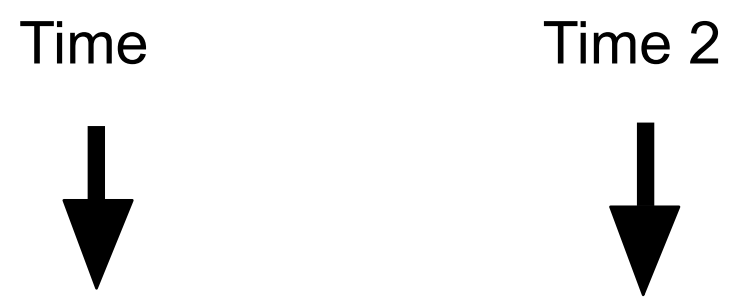

Time

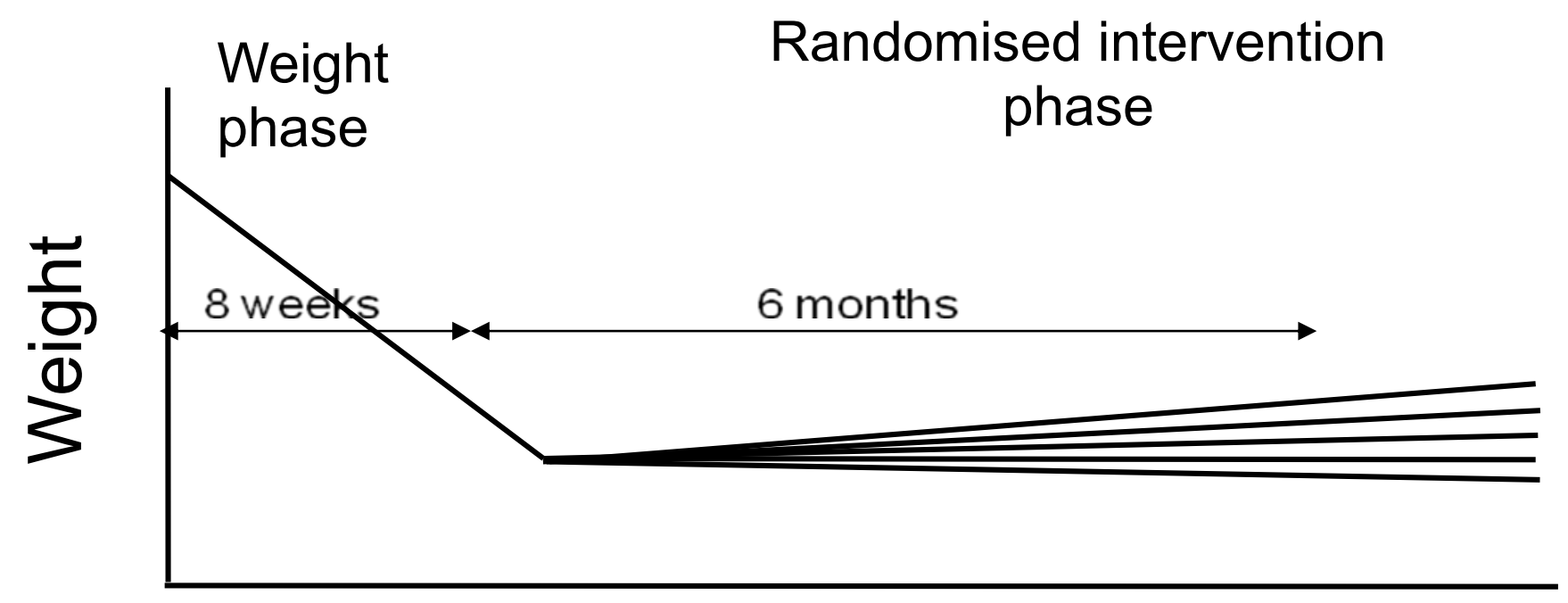

Time

Figure 1: Outline of the DiOGenes study structure 
Table 1: Relationship between TPB variables at the three time points $(n=515)$

\begin{tabular}{|c|c|c|c|}
\hline & \multicolumn{3}{|l|}{ Beta values } \\
\hline & Time 1 & Time 2 & Time 3 \\
\hline & $\begin{array}{l}\text { pre-weight } \\
\text { loss }\end{array}$ & $\begin{array}{l}\text { post-weight } \\
\text { loss/pre } \\
\text { randomisation }\end{array}$ & $\begin{array}{l}\text { post-weight } \\
\text { maintenance }\end{array}$ \\
\hline \multicolumn{4}{|l|}{ Intention } \\
\hline Cognitive Attitude & -0.006 & 0.09 & $0.21 * * *$ \\
\hline Affective Attitude & -0.07 & $-0.12^{*}$ & $-0.11^{*}$ \\
\hline Subjective Norm & 0.01 & 0.06 & $0.10^{*}$ \\
\hline Perceived Behavioural Control & 0.03 & -0.02 & $0.15^{* * *}$ \\
\hline Anticipated Affect & 0.06 & $0.17^{* * *}$ & 0.06 \\
\hline Perceived Need & $0.25 * * *$ & $0.24 * * *$ & $0.20 * * *$ \\
\hline$r^{2}$ & 0.07 & 0.09 & 0.14 \\
\hline \multicolumn{4}{|l|}{ Expectation } \\
\hline Cognitive Attitude & -0.008 & 0.08 & 0.05 \\
\hline Affective Attitude & 0.07 & 0.01 & -0.05 \\
\hline Subjective Norm & 0.005 & $0.16 * * *$ & 0.06 \\
\hline Perceived Behavioural Control & $0.30 * * *$ & $0.36 * * *$ & $0.46 * * *$ \\
\hline Anticipated Affect & 0.01 & 0.05 & $0.14 * *$ \\
\hline Perceived Need & $0.14^{* *}$ & $0.11 *$ & 0.02 \\
\hline$r^{2}$ & 0.14 & 0.21 & 0.27 \\
\hline \multicolumn{4}{|l|}{ Desire } \\
\hline Cognitive Attitude & 0.03 & $0.16 * * *$ & $0.23 * * *$ \\
\hline Affective Attitude & 0.006 & 0.03 & -0.06 \\
\hline Subjective Norm & 0.007 & $0.09 *$ & $0.09 *$ \\
\hline Perceived Behavioural Control & 0.02 & 0.006 & $0.12 * * *$ \\
\hline Anticipated Affect & 0.07 & $0.21 * * *$ & $0.16^{* * *}$ \\
\hline Perceived Need & $0.19 * * *$ & $0.20 * * *$ & $0.18^{* * *}$ \\
\hline$r^{2}$ & 0.05 & 0.18 & 0.20 \\
\hline
\end{tabular}

$*<0.05, * *<0.01, * * *<0.001$ 
Table 2: Relationship between TPB variables and weight regain

\begin{tabular}{|l|l|l|}
\hline \multirow{2}{*}{} & Beta values \\
\cline { 2 - 3 } & Time 1 & Time 2 \\
\cline { 2 - 3 } & \multirow{2}{*}{$\begin{array}{l}\text { pre-weight } \\
\text { loss }\end{array}$} & $\begin{array}{l}\text { post-weight } \\
\text { loss/pre } \\
\text { randomisation }\end{array}$ \\
\hline Starting weight & -0.06 & $-0.09^{*}$ \\
\hline Affective Attitude & 0.04 & 0.07 \\
\hline Subjective Norms & $-0.13^{*}$ & $-0.09^{*}$ \\
\hline Perceived Behavioural Control & 0.05 & \\
\hline Perceived Need & $0.24^{* * *}$ & $0.20^{* * *}$ \\
\hline $\mathbf{R}^{\mathbf{2}}$ & $\mathbf{0 . 1 1}$ & $\mathbf{0 . 0 8}$ \\
\hline
\end{tabular}

$*<0.05, * *<0.01, * * *<0.001$

Dependent variable: weight regain (weight change in intervention accounting for weight loss) Note: A negative score indicates greater weight regain associated with lower TPB scores. 